\title{
A TUTELA JURÍDICO-PENAL DOS CRIMES DIGITAIS
}

\author{
Jonathan Delli Colli, Eduardo Buzetti Eustachio Bezerro
}

Universidade do Oeste Paulista - UNOESTE, curso de Direito, Presidente Prudente, SP. E-mail: johnny.dellic@gmail.com

\begin{abstract}
RESUMO
O presente trabalho tem por objetivo abordar a tutela jurídico-penal dos crimes digitais, com enfoque na adoção de políticas legislativas para a proteção de bens jurídicos como a honra, vida, integridade física, dignidade sexual, dentre outros. Nesse intento, passamos a conceituar o crime digital, assim como seus sujeitos e suas características, e a tutela jurídica penal deste fato típico, além de demonstrar a necessidade da edição de uma legislação específica a respeito dos crimes cometidos no âmbito digital. Tomando por base a época em que o Código Penal foi publicado, torna-se evidente a incompatibilidade do diploma com as figuras típicas que surgiram com o avanço tecnológico. Em conclusão, verifica-se que para que infrações penais praticadas por meio da internet sejam efetivamente responsabilizadas e seus respectivos bens jurídicos concretamente tutelados, necessita-se com urgência a edição de uma legislação específica a respeito do assunto, tipificando tais condutas e cominando as respectivas sanções.
\end{abstract}

Palavras-chave: Tecnologia. Direito Penal. Internet. Crimes digitais. Tutela jurídica.

\section{THE LEGAL CRIMINAL PROTECTION OF DIGITAL CRIMES}

\begin{abstract}
The present work aims to address the legal protection of digital crimes, focusing on the adoption of legislative policies for the protection of legal rights such as honor, life, physical integrity, sexual dignity, among others. In this attempt, we come to conceptualize digital crime, as well as its subjects and characteristics, and the criminal legal protection of this typical fact, besides demonstrating the need to issue specific legislation regarding crimes committed in the digital scope. On the basis of the time when the Penal Code was published, it becomes clear that the diploma is incompatible with the typical figures that have emerged with technological advances. In conclusion, it is verified that in order for criminal offenses practiced through the internet to be effectively held accountable and their respective juridical assets specifically protected, it is urgently necessary to issue specific legislation on the subject, typifying such conduct and commencing the respective sanctions.
\end{abstract}

Keywords: Technology. Penal Law. Internet. Digital crimes. Legal protection.

\section{INTRODUÇÃO}

A sociedade, desde seus primórdios, enfrenta um problema que se recusa a extinguir-se: o crime. Da mesma forma que a coletividade avança no tempo e evolui através de revoluções, o crime também. A tecnologia surgiu com o propósito de melhorar a vida do homem - tanto na esfera social, como na individual. Porém, junto com ela, novas figuras típicas surgiram.

Os crimes no âmbito digital estão se tornando cada vez mais comuns no Brasil. Atualmente, não há legislação específica tratando do assunto - o que de certa forma colabora para a ocorrência dos delitos.

O caso mais recente chocou o mundo. Crianças e adolescentes de vários países começaram a cometer suicídio após entrarem em um grupo no Facebook e começarem um jogo que ficou 
conhecido como "baleia azul". Pessoas do outro lado da rede enviavam uma lista com 50 tarefas para os adolescentes fazerem - a maioria envolvia mutilação no corpo - e a última, a mais grave e chocante de todas - era o suicídio. Caso eles não as cumprissem ou quisessem desistir, eram ameaçados pelos mandantes, através da coação moral, de acordo com a reportagem feita pelo R7 (2017, s/p). As autoridades tiveram dificuldades para obter pistas e respostas sobre quem estava do outro lado da tela - justamente um dos problemas mais comuns em relação aos crimes digitais - pois a rede cibernética oferece um falso anonimato.

No Brasil, o jogo ocorreu com menos intensidade do que no exterior, mas nos fez relembrar e questionar a urgente necessidade de um tratamento legal específico para esse tipo de conduta que eventualmente choca a sociedade - que é o objetivo principal deste trabalho.

\section{METODOLOGIA}

O trabalho que segue será feito através de pesquisas em livros, documentos e outros meios bibliográficos, através do método dedutivo, demonstrando a necessidade do estudo do tema abordado.

\section{DOS CRIMES DIGITAIS}

Com a evolução dos estudos da ciência do Direito, especificamente no âmbito penal, surgiram várias teorias que apresentam um conceito geral para o crime. Atualmente, de acordo com Brandão (2016), ainda há divergências entre os doutrinadores sobre qual teoria foi adotada pelo Código Penal após a reforma feita pela Lei n. 7.209/84 (Lei de execução penal), que fez várias mudanças significativas na parte geral e especial do diploma.

São duas as teorias em destaque: a tripartida e a bipartida. A primeira conceitua crime dividindo-o em três aspectos: o fato tem que ser típico, ilícito e culpável. Já a segunda se diverge da primeira quando leciona que o crime é apenas um fato típico e ilícito, sendo a culpabilidade um pressuposto da pena. A teoria majoritária dentre os doutrinadores brasileiros é a bipartida.

Partindo da premissa do conceito geral, o estudo do crime digital fica mais fácil. A doutrina ainda diverge sobre a nomenclatura adequada, e dentre várias as apresentadas, se mostra mais apropriado nomeá-los de "crimes digitais", pois leva-se em consideração o objetivo final, que é a proteção dos dados e sujeitos no universo cibernético (CRESPO, 2015).

Há vários conceitos a respeito do crime digital, sendo o mais completo lecionado por Rossini (2004, p. 110):

O conceito de 'delito informático' poderia ser talhado como aquela conduta típica e ilícita, constitutiva de crime ou contravenção, dolosa ou culposa, comissiva ou omissiva, praticada por pessoa física ou jurídica, com o uso da informática, em ambiente de rede ou fora dele, e que ofenda, direta ou indiretamente, a segurança informática, que tem por elementos a integridade, a disponibilidade e a confidencialidade.

Entretanto, como lembra Gimenes (2013), o Código Penal brasileiro é demasiado antigo, tendo sido publicado em 1940, com sua última grande reforma em 1984 - antes do surgimento da internet - motivo pelo qual não há legislação expressa à respeito do tema, sendo então a atual legislação penal usada como base na solução de tais conflitos.

\section{CLASSIFICAÇÃO}

Os crimes em geral possuem várias classificações estabelecidas pela doutrina, seja para fins exclusivamente didáticos ou não.

Podem ser classificados, segundo Vianna (2001), em quatro grandes blocos. O primeiro deles se refere aos "próprios" - onde, especificamente, o bem jurídico tutelado pelo direito penal 
é a inviolabilidade dos dados; depois em "impróprios" - caracterizando-se pelo uso do computador como instrumento-meio para a prática dos delitos, porém sem ofender a inviolabilidade dos dados; seguido dos "mistos" - sendo considerados complexos, pois há mais de um bem jurídico tutelado; e por fim em "mediatos" - que ocorrem quando um crime informático é utilizado como meio para a realização de outro crime, não informático.

Devemos ainda levar em conta que o avanço da tecnologia nos dias atuais é demasiado rápido, havendo a possibilidade de novas espécies ou classificações surgirem com o passar do tempo.

\section{SUJEITOS}

Ordinariamente, os sujeitos do crime são divididos em dois grupos: o ativo e o passivo.

Seguindo o raciocínio de Mirabete (2016), o conceito de sujeito ativo do crime pode ser dado como "aquele que pratica a conduta descrita na lei", sendo assim o autor do crime. Ressalta ainda que somente o homem, de forma isolada ou em conjunto, pode ser considerado sujeito ativo.

Nos crimes digitais, o sujeito ativo recebe nomenclatura própria, pois há uma peculiaridade à respeito deles: são ausentes fisicamente - que, consequentemente, torna-se um obstáculo para garantir a identidade do infrator. A primeira nomenclatura é a de hacker: alguém que possui enorme conhecimento na área digital. O segundo é cracker: também é alguém que tem grandes conhecimentos nessa área. O que diferencia o primeiro do segundo é o objetivo: àquele não destrói ou prejudica os dados que consegue acessar. Já o segundo utiliza seu conhecimento para tirar vantagens próprias e causar danos a outrem (GIMENES, 2013).

Damásio de Jesus (2017), conceitua que o sujeito passivo do delito é o titular do interesse que foi ofendido com a prática do crime pelo sujeito ativo. Subdivide o sujeito passivo em duas espécies: o constante e o eventual. $O$ primeiro se dá pois, juridicamente, sempre haverá um sujeito passivo pelo simples motivo do delito ter sido praticado, sendo este o Estado. $O$ segundo se refere ao titular do interesse penalmente protegido, sendo o homem o personagem principal.

\section{JURISDIÇÃO E COMPETÊNCIA}

Um dos maiores problemas com relação à efetiva resolução dos crimes, no âmbito digital, se dá por conta da fixação da jurisdição e da competência. A jurisdição é uma das funções do Estado, onde ele substitui as partes na solução dos conflitos. Embora seja um poder único, é repartido em vários órgãos do Estado, por praticidade. Surge a competência - uma dessas repartições - que é o limite de atuação do juiz em determinado território (VINICIUS, 2017).

Como decidir, então, qual juiz será competente se o crime não é praticado no meio físico? Como esclarece Vianna (2001), a Constituição Federal resolve esse problema, já que seu art. 109, IV, fixa a competência dos juízes federais em razão da matéria (natureza do crime) - declarando que “(...) as infrações penais praticadas em detrimento de bens, serviços ou interesses da União (...)". Por ser uma espécie de serviço de telecomunicação, sujeita-se à regulamentação da ANATEL, sendo de interesse da União a proteção jurídica. Dessa forma, quando o acesso à internet for utilizado para o cometimento de crimes, a competência será da Justiça Federal.

O mesmo não ocorre quando a internet não é utilizada para o apossamento de dados indevidamente. Como o professor Bonfim esclarece, o Código de Processo Penal adotou, em seu art. 70, a teoria do resultado com relação ao lugar do crime. Assim, a competência será do local onde se encontre o computador violado, pois, nesse local, é onde houve a consumação delituosa.

\section{DA TUTELA JURÍDICA DOS CRIMES DIGITAIS}


Entende-se por tutela jurídica a proteção dos direitos enunciados pelo legislador, podendo ser de cunho material ou processual. A tutela atinge seu objetivo final quando o direito é efetivamente protegido ou é devidamente realizado (MARINONI, 2003).

Como citado anteriormente, a tecnologia avança rapidamente numa velocidade que, às vezes, o Direito não consegue acompanhar de imediato. Consequentemente, novos direitos, obrigações e deveres surgem. Tais acontecimentos são novidade para o ordenamento jurídico, e nem sempre estão protegidos expressamente pela legislação.

Surgiu então a chamada quinta geração dos direitos fundamentais, que trata sobre os direitos inerentes ao meio cibernético, como explica Rangel (2013). Tal ocorrência demonstra a séria importância do reconhecimento do Direito com relação à tutela dos direitos no âmbito tecnológico, que tem suas próprias características peculiares.

No âmbito penal, a tutela jurídica dos crimes digitais é de suma importância para a sociedade, pois visa protegê-la daqueles, que vêm surgindo com frequência desde o último século. O objeto do crime como o acesso alheio às informações pessoais, dados, imagens, vídeos, fotos devem ser resguardados na lei penal, a fim de amparar àqueles que têm sua esfera particular invadida no meio digital.

\section{LEGISLAÇÃO ATUAL}

Hodiernamente, ainda há dificuldades na investigação e punição de todos os autores que praticam os crimes digitais, visto que não há legislação específica pertinente que regule tal tipo de delito, e por consequência alguns dos fatos acabam por impunes e sem solução. Por esse motivo, cresce cada vez mais a necessidade e a urgência para que uma legislação seja editada à cerca do tema, e que tente abranger a maior amplitude possível para evitar que lacunas apareçam.

Em 2012, após um caso traumático sofrido pela atriz Carolina Dieckmann, onde ela teve seu computador invadido e suas fotos intimas expostas na internet, além de sofrer ameaças de extorsão por parte dos criminosos, para evitar que mais fotos fossem expostas. Com base nesses acontecimentos, foi editada uma lei que tipifica os delitos digitais impróprios.

\section{LEI 12.737/12 (LEI CAROLINA DIECKMANN)}

A atriz Carolina Dieckmann, da rede Globo, teve seu computador invadido por hackers e teve fotos íntimas divulgadas na internet, segundo o site $(G 1,2013, s / p)$. Após a repercussão do caso, foi editada a lei 12.737/12, que incluiu os dispositivos 154-A e 154-B e modificou a redação dos arts. 266 e 298, todos do Código Penal.

Tem como principal objetivo tipificar os delitos informáticos próprios, que são aqueles em que os dados digitais são o objeto do crime. Ressalta Buzzi (2016), que, embora a lei não seja específica com relação aos fatos ocorridos com a atriz (divulgação de fotos e vídeos íntimos), a lei tutela de forma geral os casos de pornografia não consensual expostos na rede digital.

Interessante o comentário que um professor autor do volume de direito penal da coleção Saberes do Direito à respeito do tema em seu blog. Explica Cabette (2013):

É interessante notar que a legislação sob comento acabou ganhando o epíteto de "Lei Carolina Dieckmann", atriz da Rede Globo de televisão que foi vítima de invasão indevida de imagens contidas em sistema informático de natureza privada e cujo episódio acabou acelerando o andamento de projetos que já tramitavam com o fito de regulamentar essas práticas invasivas perpetradas em meios informáticos para modernização do Código Penal Brasileiro. Antes disso, era necessário tentar tipificar as condutas nos crimes já existentes, nem sempre de forma perfeita. A questão, sob esse ponto de vista, é agora solucionada pela Lei $12.737 / 12$. 
É de se notar que este foi um grande avanço para a legislação penal brasileira. Porém, reitera-se que os crimes digitais impróprios ainda não estão regulados, e este acaba sendo um dos motivos que o fazem acontecer com mais frequência.

\section{PROJETO DE LEI PARA CRIMINALIZAR A PORNOGRAFIA POR VINGANÇA}

Atualmente, uma nova forma de vingança vem se tornando muito comum no meio informático. Conhecida popularmente e pela mídia como "pornografia por vingança", João de Melo (2016) nos explica que ela é praticada em maior porcentagem por homens que não aceitam o término do relacionamento com suas companheiras - e decidem se vingar com postagens de fotos de nudez e vídeos pornográficos na internet - onde, na maioria das vezes, a mulher é a personagem principal.

A prática se tornou tão comum que acabou por originar um projeto de lei que torna esse tipo de ação um crime federal nos Estados Unidos. Prossegue o autor dizendo que, como hodiernamente tal função é tarefa dos estados, ainda faltam alguns adeptos, visto que apenas 34 dos 50 estados estadunidenses se manifestaram sobre o assunto.

Ainda seguindo de acordo com o pensamento do autor, tal vingança às vezes extrapola e passa a produzir efeitos permanentes nas vítimas. Exemplificando, é citado um caso em que o exnamorado de uma jovem publicou tais vídeos na página do Facebook da empresa em que ela trabalhava, e ela acabou por ser demitida e ficou com sérias dificuldades de conseguir outro emprego.

No Brasil, não há lei que o tipifica como crime, talvez sendo um dos motivos pelo qual ele cresce cada vez mais no âmbito nacional, e, como no exterior, a mulher é a principal vítima. Atualmente, pela falta de legislação, aplica-se aos casos o art. 139 do Código Penal (crime de difamação), além da possibilidade de ser aplicada a Lei Maria da Penha, segundo a revista Época.

Desta forma, conclui-se que é de suma importância a publicação de uma lei tratando sobre a matéria, tipificando tal conduta como crime e cominando penas equivalentes aos danos causados pelos autores às vítimas, sem prejuízo de possível indenização.

\section{CONCLUSÃO}

Por fim, com a vasta inovação da tecnologia diariamente, várias são as hipóteses jurídicas penais que surgem em paralelo, devendo o direito, como uma ciência social, se manter em constante mudança.

Os recentes crimes praticados na esfera digital estão se tornando cada vez mais comuns por conta de uma característica peculiar: o anonimato. Por estarem atrás de uma máquina, os agentes criminosos alimentam a falsa sensação de impunidade.

Não se nega que existe uma maior dificuldade para a resolução desses tipos de condutas, exatamente por não estarem ocorrendo no meio físico, e pela falta de legislação no Brasil à respeito do assunto. Porém, como citado acima, a sensação de impunidade se torna falsa à medida em que novas instrumentos de investigação no âmbito digital surgem juntamente com o avanço da tecnologia, facilitando, desta forma, a solução dos casos.

Dessa forma, resta claro a importância da edição de uma legislação pertinente aos crimes praticados na internet, para que se possa ter uma maior precisão e agilidade na resolução dos crimes, afastando essa sensação de impunidade, e consequentemente, diminuindo o número de casos praticados nessa área.

\section{BIBLIOGRAFIA}

BRANDÃO, Cláudio. Teoria Jurídica Do Crime, (V. 1), 4ạ edição. Atlas, 11/2014. [Minha Biblioteca]. - pág. 17 
BRASIL. Congresso Nacional. Lei Carolina Dieckmann. Lei no 12.737 de 30 de novembro de 2012. Dispõe sobre a tipificação dos crimes informáticos próprios. Diário Oficial da União. Brasília, DF, 30 de novembro de 2012. Disponível em: <http://www.planalto.gov.br/ccivil_03/_ato20112014/2012/lei/l12737.htm>. Acesso em: 27 de julho de 2017.

BRASIL, Constituição (1988). Constituição da República Federativa do Brasil. Brasília: Senado Federal, 1988.

BUZZI, Vitória De Macedo et al. Pornografia de vingança: contexto histórico-social e abordagem no direito brasileiro. 2015.

CRESPO, Marcelo Xavier de Freitas. Crimes Digitais. São Paulo: Saraiva, 2011.

CABETTE, Eduardo Luiz Santos. Atualidades do Direito, 2013. Disponível em: <http://atualidadesdodireito.com.br/blog/2013/01/03/novos-artigos-no-codigo-penal/>. Acesso em 19 de julho de 2017.

G1 - O Portal de Notícias da Globo. Lei "Carolina Dieckmann”, que pune invasão de PCs, entra em vigor, 2013. Disponível em <http://g1.globo.com/tecnologia/noticia/2013/04/lei-carolinadieckmann-que-pune-invasao-de-pcs-passa-valer-amanha.html>. Acesso em: 02 de agosto de 2017.

GIMENES, Emanuel Alberto Sperandio Garcia. Crimes virtuais, 2013. Disponível em: <http://www.revista doutrina.trf4.jus.br/artigos/edicao055/Emanuel Gimenes.html>. Acesso em: 17 de julho de 2017.

MELO, Ozório João. Projeto de lei quer criminalizar pornografia por vingança nos EUA. Consultor Jurídico. 2016. Disponível em: http://www.conjur.com.br/2016-jul-19/projeto-lei-criminalizarpornografia-vinganca-eua>. Acesso em: 02 de agosto de 2017.

MARINONI, Luiz Guilherme. Tutela inibitória, p. 32. São Paulo, 3a ed. RT, 2003.

MIRABETE, Júlio Fabbrini. Manual de Direito Penal: Parte Geral. São Paulo. Atlas, 2016.

R7 - O Portal de Notícias da Record. "Eu gosto de ver as pessoas sofrerem", diz curador da Baleia Azul encontrado por reportagem da Record TV, maio de 2017 . Disponível em <http://noticias.r7.com/brasil/eu-gosto-de-ver-as-pessoas-sofrerem-diz-curador-da-baleia-azulencontrado-por-reportagem-da-recordtv-31052017>. Acesso em: 04 de agosto de 2017.

RANGEL, Tauã Lima Verdan. A tutela jurídica do meio ambiente cibernético: a oxigenação propiciada pelos direitos humanos de quinta dimensão. Âmbito Jurídico, Rio Grande, XVI, n. 115, 2013. Disponível em: <http://www.ambito juridico.com.br/site/?n link=revista artigos leitura\&artigo id=13037>. Acesso em 04 de agosto de 2017.

VARELLA, Gabriela; SOPRANA, Paula. Pornografia por vingança: crime rápido, trauma permanente, 2016. Disponível em: <http://epoca.globo.com/vida/experienciasdigitais/noticia/2016/02/pornografia-de-vinganca-crime-rapido-trauma-permanentee.html>.

Acesso em: 02 de agosto de 2017. 
VIANNA, Túlio Lima. Do acesso não autorizado a sistemas computacionais: fundamentos do direito penal informático. Mestrando em ciências penais na Universidade Federal de Minas Gerais. 2001. Disponível em: <http://www.bibliotecadigital.ufmg.br/dspace/handle/1843/BUOS-96MPWG>. Acesso em: 28 de julho de 2017. 